\title{
Erratum to: Ammonium Nitrogen Deposition as a Dominant Source of Nitrogen in a Forested Watershed Experiencing Acid Rain in Central Japan
}

\author{
Young-Sik Ham • Hiromi Kobori • \\ Joo-Hyon Kang • Joon Ha Kim
}

Published online: 8 April 2010

(C) Springer Science+Business Media B.V. 2010

\section{Erratum to: Water Air Soil Pollut \\ DOI 10.1007/s11270-010-0347-7}

Unfortunately, the affiliations of Joo-Hyon Kang and Joon Ha Kim were published with errors. The correct affiliations are shown here.

The online version of the original article can be found at http:// dx.doi.org/10.1007/s11270-010-0347-7.

\footnotetext{
Y.-S. Ham $(\bowtie)$

The Council for Paldang Water Quality Policy, 559-21 Yangsu-ri,

Yangseo-myeon, Yangpyeong-gun, Gyonggi-Do 476-823,

Republic of Korea

e-mail: hamy007@msn.com

H. Kobori

Faculty of Environmental and Information Studies,

Tokyo City University,

3-3-1 Ushikubo-nishi, Tsuzuki-ku,

Yokohama 224-0015, Japan

J.-H. Kang

Department of Civil and Environmental Engineering,

Dongguk University-Seoul,

26 Pil-dong 3-ga Jung-gu,

Seoul 100-715, Republic of Korea

J. H. Kim

Department of Environmental Science and Engineering,

Gwangju Institute of Science and Technology,

Gwangju 500-712, Korea
} 